\title{
Laparoscopic Repair of Perforated Duodenal Ulcer
}

\author{
Dr. H. V. Neralekar ${ }^{1}$, Dr. Aditya Phadke ${ }^{2}$, Dr. Mahesh Reddy ${ }^{3}$, Dr. Madhavendra Kabra ${ }^{4}$ \\ ${ }^{1}$ Associate Professor, Department of Surgery, Krishna Hospital, Karad \\ ${ }^{2}$ Resident, Department of Surgery, Krishna Hospital, Karad \\ ${ }^{3}$ Resident, Department of Surgery, Krishna Hospital, Karad \\ ${ }^{4}$ Resident, Department of Surgery, Krishna Hospital, Karad
}

\begin{abstract}
Although prevalence of peptic ulcer is decreasing, the number of duodenal ulcer perforations appears to be unchanged. This complication of duodenal ulcer is traditionally surgically treated. Laparoscopic treatment of perforated duodenal ulcer has been described as safe and advantageous compared to open technique but advantages are still not clear due to small number of cases in published studies. Based on these recommendations we decided to study the effectiveness of laparoscopic treatment of perforated peptic duodenal ulcer. In this prospective study we evaluated the first 10 patients at KRISHNA HOSPITAL,KARAD in whom we performed laparoscopic repair of perforated duodenal ulcer. There were no conversions to open procedure and no early postoperative complications. The patients were contacted by phone a year after the operation, and all were satisfied with the operation and the appearance of postoperative scars. No postoperative complications were noted. Laparoscopic repair of selected patients with perforated duodenal ulcer is a safe and effective method if adequate expertise is achieved.
\end{abstract}

Keywords: peptic ulcer, laparoscopic approach, minimally invasive surgery

\section{Introduction}

Peptic ulcer disease is a common condition with Helicobacter pylori infection and use of nonsteroidal anti-inflammatory drugs being the most common etiologic factors ${ }^{1}$. Although the use of $\mathrm{H} 2$ receptor blockers and proton pump inhibitors has led to a decrease in peptic ulcer prevalence, it seems that rates of peptic ulcer complications remained unchanged or even slightly increa-sed ${ }^{2,3}$. Laparoscopic repair of perforated peptic ulcer was introduced in 1989 by Mouret who used fibrin glue and omental patch ${ }^{4}$. A year later, Nathanson et al. described the suture repair of perforated peptic ulcer ${ }^{5}$. Since then many efforts have been made to compare laparoscopic and open repair, respectively ${ }^{6-12}$. However, recent papers suggest that laparoscopic repair is safe and effective pro-cedure in selected patients, offering shorter operating time, less postoperative pain and shorter postoperative hospital stay ${ }^{6,12}$. Here we present our first 10 patients with perforated duodenal ulcers who were treated laparoscopically, using an omental patch closure.

\section{Materials and Methods}

In this prospective study we included first 10 patients which underwent laparoscopic repair of perforated duo-denal ulcer at our department. The patients were admit-ted in urgent setting. A detailed history was taken, the patients were examined. In each case, exact moment in which the symptoms appeared was established, and the time from the onset of symptoms to the beginning of the operation was recorded. Main diagnostic procedure we performed was abdominal X-ray in erect position. In two cases, additional abdominal ultrasound examination was carried out. A standard work-up was performed, which included complete blood count and serum concentrations of glucose, urea, creatinine, protein, albumin and bilirubin.
Before the start of the operation, patients received prophylactic antibiotic therapy consisting of metronidazole and gentamycin in 6 cases or metronidazole and cefotaxime in 4 cases.

The operation started with a supraumbilical incision, through which a Veress needle was inserted, and pneumoperitoneum of $14 \mathrm{~mm} \mathrm{Hg}$ was achieved. A 10-mm port was inserted, which was used for laparoscope. Under vi-sual control two additional ports were placed, a 10-mm port approximately in the middle between the xiphoid process and umbilicus, slightly paramedian to the left and a $5-\mathrm{mm}$ port in the right medioclavicular line below the costal margin. Exploration of the abdominal cavity was performed and the site of perforation was established. It was then closed with interrupted resorbable sutures (catgut/wikryl), using intracorporal tying technique. A part of omentum was then positioned over the site of perforation and fixed with single resorbable suture that was placed away from the site of perforation. (omental patch).Abdominal cav-ity was thoroughly lavaged; a Ch 14 abdominal drain was positioned through the right subcostal port.

The duration of each operation was recorded in 5--minute intervals. After the operation the patients were transferred to the surgical intensive care unit(sicu). A standardized postoperative treatment protocol was carried out. The patients received proton pump inhibitor pantoprazol (inj.pan40), intravenously while in hospital and orally after the discharge. Thromboprophylaxis with enoxaparin (Clexane) was administered during the entire postoperative hospital stay. Nasogastric suction and prophylactic antibiotic therapy was discontinued 48 hours after the operation and enteral nutrition was commenced on the third postoperative day.

A year after the operation the patients were contacted by phone. They were asked to evaluate the appearance of 


\section{International Journal of Science and Research (IJSR) \\ ISSN (Online): 2319-7064 \\ Index Copernicus Value (2013): 6.14 | Impact Factor (2014): 5.611}

postoperative scars and their overall satisfaction with the treatment with marks from 1 to 5 ( 5 being the best mark). They were also asked if they had any postoperative symptoms related to the operation or similar to symptoms that preceded the operation.

\section{Results}

There were 10 patients between January 2001 and January 2008 who underwent laparoscopic repair of perforated peptic duodenal ulcer. Six were males and four females; mean age was 42 (range 29-70) years. Diagnosis of peptic ulcer was established prior to the onset of symptoms that led to the operation in only one case. Other patients had no earlier symptoms related to upper gastrointestinal tract. All the patients had elevated white blood count, with mean value of $12.2^{\prime} 10^{9} / \mathrm{L}$ (range $10.5^{\prime} 10^{9} / \mathrm{L}-14.7^{\prime} 10^{9} / \mathrm{L}$ ), other laboratory test results were not significant. Mean time from the onset of symptoms to the be-ginning of the operation was 5 hours (range 3 to 6 hours). In 9 cases, operation was indicated on basis of pneumoperitoneum that was evident in abdominal X-ray taken in erect position. In one case, erect abdominal X-ray was negative for pneumoperitoneum, so the operation was started as exploratory laparoscopy for acute abdomen. The diagnosis of perforated duodenal ulcer was established intraoperatively. In 4 cases, the site of perfo-ration was closed using two interrupted stitches and in 6 cases a single stitch was sufficient for closure of the perforation site.

Mean duration of the operation was 80 (range 60-80) minutes. Abdominal drain was removed after 2 ( 7 cases) or 3 ( 3 cases) days. Early postoperative period was in all cases uneventful. Mean postoperative hospital stay was 5 (range 5-7) days. Control gastroscopy was performed 8 weeks postoperatively and was negative in all cases. When contacted by phone, the patients have equivocally graded the appearance of postoperative scars and their satisfac-tion with the procedure with the highest mark, 5. Only one patient experienced intermittent pain in epigastric region after the operation. This was the patient who was diagnosed with duodenal peptic ulcer prior to the operation.

\section{Discussion and Conclusion}

Laparoscopic treatment of perforated duodenal peptic ulcer is yet another example where laparoscopic appro-ach is replacing traditional operation that has been wide-ly used for decades. This operation does not require re-moval of tissue, as is the case with splenectomy and colon resection that necessitates minilaparotomy. Recently pub-lished papers generally recommend laparoscopic repair of perforated peptic duodenal ulcer as a safe and effective method for selected patients, although they are cautious because of relatively small number of cases ${ }^{7}$. Even when published studies were pooled in meta-analysis, the out-come concerning possible advantages of laparoscopic approach to perforated duodenal ulcer was not clear ${ }^{8,13}$.

Our study confirms the safety of laparoscopic approach in treatment of perforated peptic duodenal ulcer. We had no conversions to open procedure and no complications in early postoperative period. Although this can-not be verified statistically because of small number of cases, the patients in this study were earlier discharged from the hospital than the patients who had their perfo-rated duodenal ulcer operated using open approach. The only disadvantage of the laparoscopic approach could be slightly longer duration of operation. Based on these encouraging early results, we continue our efforts to per-form laparoscopic treatment of perforated duodenal ulcer whenever feasible.

\section{References}

[1] RAMAKRISHNAN K, SALINAS RC, Am Fam Physician, 76 (2007) 1005. -

[2] POST PN, KUIPERS EJ, MEIJER GA, Aliment Pharmacol Ther, 23 (2006) 1587. -

[3] TAHA AS, ANGERSON WJ, PRASAD R, MCCLOSKEY C, GILMOUR D, MORRAN CG, Aliment Pharmacol Ther, 28 (2008) 878. -

[4] MOURET P, FRANÇOIS Y, VIGNAL J, BARTH X, LOM-BARD-PLATET R, Br J Surg, 77 (1990) 1006. -

[5] NATHANSON LK, EASTER DW, CUSCHIERI A, Surg Endosc, 4 (1990) 232. -

[6] BHOGAL RH, ATHWAL R, DURKIN D, DEAKIN M, CHERUVU CN, World J Surg, 32 (2008) 2371. -

[7] ATES M, SEVIL S, BAKIRCIOGLU E, COLAK C, J Laparoendosc Adv Surg Tech A, 17 (2007) 615. — 8. SANABRIA AE, MORALES CH, VILLEGAS MI, Cochrane Database Syst Rev, 19 (2005) CD004778. -

[8] LUNEVICIUS R, MORKEVICIUS M, Surg Endosc, 19 (2005) 1565 . -

[9] LUNEVICIUS R, MORKEVICIUS M, Br J Surg, 92 (2005) 1195. -

[10] LAU WY, LEUNG KL, KWONG KH, DAVEY IC, ROB-ERTSON C, DAWSON JJ, CHUNG SC, LI AK, Ann Surg, 224 (1996) 131.

[11] SIU WT, LEONG HT, LAW BK, CHAU CH, LI AC, FUNG KH, TAI YP, LI MK, Ann Surg, 235 (2002) 313. -

[12] LAU H, Surg Endosc, 18 (2004) 1013. 